\title{
Factors affecting urate solubility in vitro
}

\author{
IAN KIPPEN, JAMES R. KLINENBERG, ALAN WEINBERGER, \\ AND WILLIAM R. WILCOX \\ From the Departments of Pharmacology and Medicine, UCLA School of Medicine; the Divisions of Medicine, \\ Cedars-Sinai Medical Center; and the Departments of Chemical Engineering and Materials Science, University \\ of Southern California, Los Angeles, California
}

Acute gouty arthritis occurs when crystals of monosodium urate form and deposit in joints and connective tissue. These crystals then provoke the characteristic acute inflammatory response of gout (Seegmiller, 1965), and may accumulate chronically forming gouty tophi.

Although deposition of urate crystals from hyperuricaemic body fluids is an essential requirement in the pathogenesis of gout, only a small percentage of hyperuricaemic individuals ever shows clinical signs of gout. The factor or factors predisposing certain hyperuricaemic persons and not others to develop gout are as yet unknown. Thus, it is important for an understanding of the pathogenesis of gout to examine the factors which influence urate solubility and which may ultimately prove to be responsible for the initiation of urate crystal formation.

Factors presently known to influence urate solubility include $\mathrm{pH}$, temperature, ionic strength, and the binding of urate to macromolecules, such as plasma proteins and mucopolysaccharides of connective tissue. We have recently published a theoretical discussion of factors influencing urate solubility (Wilcox, Khalaf, Weinberger, Kippen, and Klinenberg, 1972). The present communication summarizes the results of laboratory studies designed to further quantify some parameters of urate solubility in buffers and biological fluids.

\section{Materials and methods}

Monosodium urate was either purchased from $\mathbf{K} \& \mathbf{K}$ Laboratories, Inc. (Plainview, N.Y.) or prepared from uric acid as previously described (Buchanan, Klinenberg, and Seegmiller, 1965). Human crystalline albumin (Pentex, Grade B, electrophoretically pure) and PIPES (Piperazine $\mathrm{N}, \mathrm{N}^{\prime}$-bis (2-ethane sulfonic acid)) were purchased from Calbiochem (La Jolla, Calif.). Uricase from hog liver was obtained from Worthington Biochemical (Freehold, New Jersey).

Sodium urate was determined as uric acid (using a molecular weight of 168.11) by an enzymatic spectrophotometric method (Liddle, Seegmiller, and Laster, 1959) using a Gilford Model 2400 spectrophotometer. All pH determinations were made with a Corning Model $112 \mathrm{pH}$ meter. Centrifugation was done in a Sorvall RC2-B centrifuge equipped with a Sorvall SS-34 head.

\section{DETERMINATION OF URATE SOLUBILITY}

To determine the urate solubility of each solution, three $\mathrm{ml}$ of the solution to be tested was added to a $16 \mathrm{ml}$ glass test tube containing a small magnetic stirring bar. The test tubes were placed on a magnetic stirrer and maintained at the desired temperature. After 16 hours the solutions were centrifuged at $12,000 \mathrm{~g}$ in a $6 \mathrm{ml}$ glass centrifuge tube and the supernatant was removed. The centrifugation was repeated until no precipitate was visible. Two centrifugations were usually sufficient. The final supernatant was then assayed for urate. Using this procedure, urate crystals could not be detected in the final supernatant by light microscopy. Care was taken to maintain the desired temperature closely during all steps of the procedure including centrifugation.

\section{URATE SOLUBILITY IN BUFFER SOLUTIONS}

The effect of sodium on urate solubility was determined

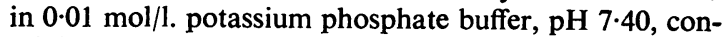
taining appropriate amounts of sodium chloride. The desired $\mathrm{pH}$ was obtained by titrating solutions of monobasic and dibasic potassium phosphate.

The effect of $\mathrm{pH}$ on urate solubility was determined in $0.01 \mathrm{~mol} / \mathrm{l}$. sodium phosphate buffer containing $0.15 \mathrm{~mol} / \mathrm{l}$. sodium chloride and adjusted to the desired $\mathrm{pH}$ by titrating solutions of monobasic and tribasic sodium phosphate.

The effect of albumin on urate solubility was determined by adding the appropriate amount of albumin to $3 \mathrm{ml} 0.01 \mathrm{~mol} / \mathrm{l}$. sodium phosphate buffer, $\mathrm{pH} 7 \cdot 40$, containing $0.15 \mathrm{~mol} / \mathrm{l}$. sodium chloride and $100 \mathrm{mg} / 100 \mathrm{ml}$ sodium urate. The albumin was dissolved by gentle mixing.

All buffers were boiled before use. Excess sodium urate (approximately $100 \mathrm{mg} / 100 \mathrm{ml}$ ) was added to solutions before titration to prevent $\mathrm{pH}$ changes due to the urate itself.

URATE SOLUBILITY IN BIOLOGICAL FLUIDS All blood and urine samples were obtained from normal volunteers. Blood was drawn in heparinized vacutainers, separated by centrifugation for 10 minutes at 3500 r.p.m. and the plasma frozen at $-20^{\circ} \mathrm{C}$ until the time of assay (not 
more than 2 weeks). Ultrafiltrates of plasma were prepared by negative pressure ultrafiltration through a collodion membrane. Before assay for urate solubility, three $\mathrm{ml}$ aliquots of some plasma samples were dialysed for 16 hours at $4^{\circ} \mathrm{C}$ against $0.01 \mathrm{~mol} / \mathrm{l}$. sodium phosphate buffer, pH 7.4, with or without $0 \cdot 15 \mathrm{~mol} / 1$. sodium chloride. Synovial fluid samples were obtained from patients with inflammatory or traumatic arthritis. None of the subjects from which biological fluid samples were obtained were taking drugs known to inhibit urate binding to macromolecules (Bluestone, Kippen, and Klinenberg, 1969; Whitehouse, Kippen, and Klinenberg, 1971). $3 \mathrm{ml}$ of each fluid to be tested was placed in a glass test tube with a small magnetic stirring bar. $10 \mathrm{mg}$ sodium urate were added and the sample incubated for 16 hours at $37^{\circ} \mathrm{C}$ with slow stirring. After $16 \mathrm{hrs}$ each sample was subjected to the centrifugation procedure described above, and the final supernatant assayed for urate.

\section{Results}

Fig. 1 shows the effect of sodium chloride concentration on sodium urate solubility in $0.01 \mathrm{~mol} / \mathrm{l}$. potassium phosphate buffer, $\mathrm{pH} 7 \cdot 40$, at $37^{\circ} \mathrm{C}$ and $26^{\circ} \mathrm{C}$. The curves are least-squares fits to the data.

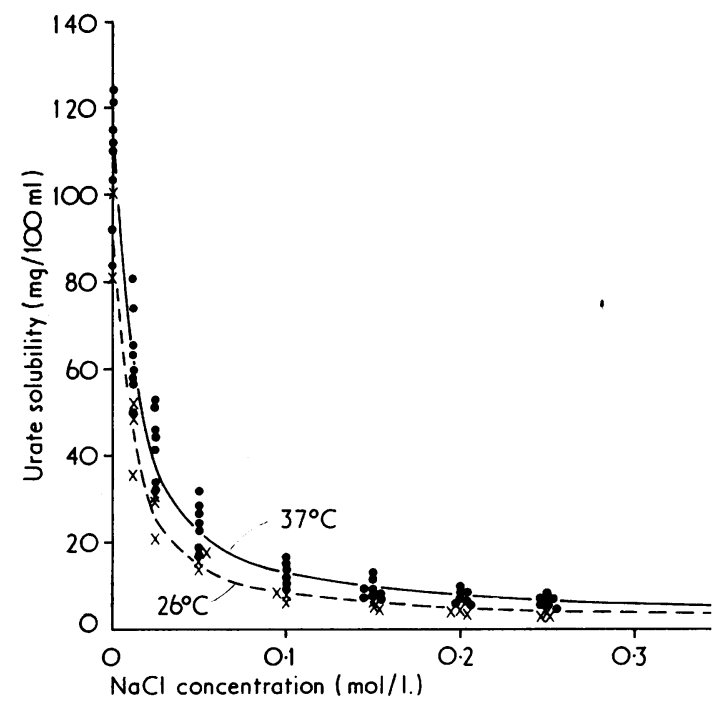

FIG. 1 Effect of sodium chloride on sodium urate solubility in 0.01 molll. potassium phosphate buffer, $\mathrm{pH} 7 \cdot 4$, at $37^{\circ} \mathrm{C}(\bullet)$ and $26^{\circ} \mathrm{C}(\times)$, using sodium urate $(K \& \mathrm{~K}$ Laboratories). The curves are least-squares fits to the data

At a concentration of $0 \cdot 12 \mathrm{~mol} / \mathrm{l}$. sodium chloride, the solubility of sodium urate is less than $10 \%$ of the low salt value. Over the physiological range from about 0.13 to $0.15 \mathrm{~mol} / \mathrm{l}$., there is little additional effect of increasing sodium concentration. Urate solubility is approximately $40 \%$ less at $26^{\circ} \mathrm{C}$ than at $37^{\circ} \mathrm{C}$ over the entire range of the curves.

Fig. 2 shows the effect of $\mathrm{pH}$ on sodium urate solubility in $0.01 \mathrm{~mol} / \mathrm{l}$. sodium phosphate buffer,

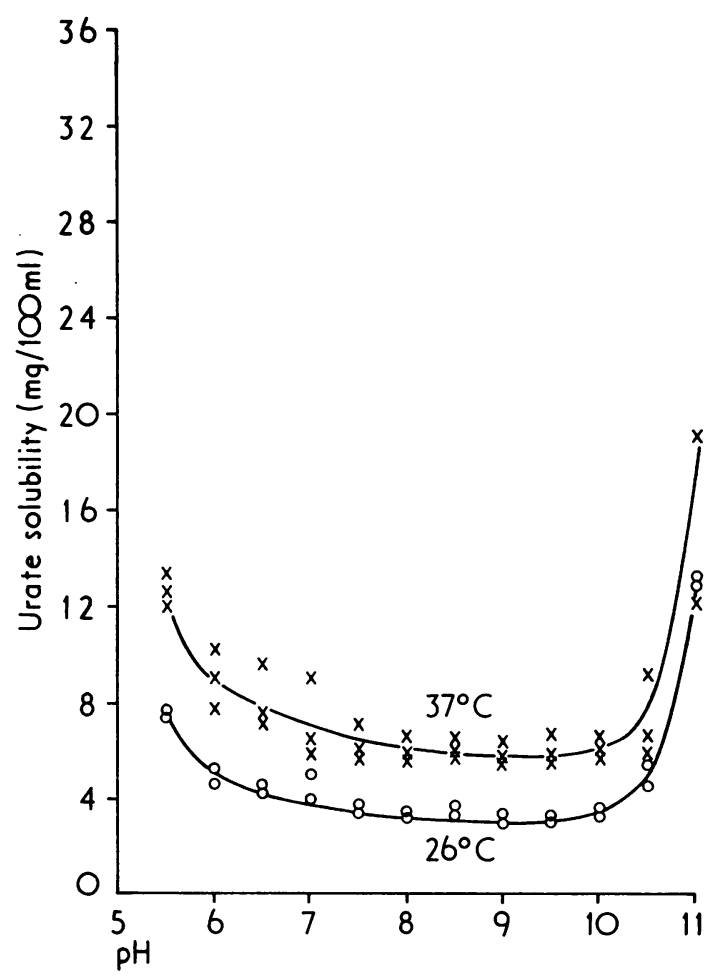

FIG. 2 Effect of $p H$ on sodium urate solubility in 0.01 molll. sodium phosphate buffer containing $0.15 \mathrm{~mol} / \mathrm{l}$. sodium chloride at $37^{\circ} \mathrm{C}(\times)$ and $26^{\circ} \mathrm{C}(\mathrm{O})$

pH $7 \cdot 40$, containing $0 \cdot 15 \mathrm{~mol} / 1$. sodium chloride. The urate solubility is $6.6 \mathrm{mg} / 100 \mathrm{ml}$ at $37^{\circ} \mathrm{C}$ and $3.7 \mathrm{mg} /$ $100 \mathrm{ml}$ at $26^{\circ} \mathrm{C}$.

Fig. 3 shows the effect of albumin on sodium urate solubility at $4^{\circ} \mathrm{C}, 26^{\circ} \mathrm{C}$, and $37^{\circ} \mathrm{C}$. The curves have a sigmoid shape at all temperatures. The increase in urate solubility produced by $50 \mathrm{mg} / \mathrm{ml}$ albumin is $45 \%$ at $4{ }^{\circ} \mathrm{C}, 44 \%$ at $26^{\circ} \mathrm{C}$, and $41 \%$ at $37^{\circ} \mathrm{C}$.

Fig. 4 shows the solubility of sodium urate in biological fluids. The mean values in $\mathrm{mg} / 100 \mathrm{ml}$ plus or minus one standard error of the mean are as follows: plasma 10.6 \pm 0.5 ; plasma dialysed against 0.01 mol/l. sodium phosphate buffer, pH 7.40, 49.5 $\pm 0 \cdot 6$; plasma dialysed against the same phosphate buffer containing $0.15 \mathrm{~mol} / \mathrm{l}$. sodium chloride, $10 \cdot 7 \pm 0.5$; urine $21 \cdot 4 \pm 1.9$; and synovial fluid 10.0 \pm 0.7 . Dialysing plasma against the sodium chloridecontaining buffer did not change the urate solubility, whereas dialysing plasma against the buffer not containing sodium chloride resulted in a fivefold increase in urate solubility. The mean value for urate solubility in urine was about twice that of plasma and considerably more variable.

Fig. 5 shows the effect of ultrafiltration on urate solubility in plasma. In almost every case the urate solubility in a plasma ultrafiltrate was lower than in 


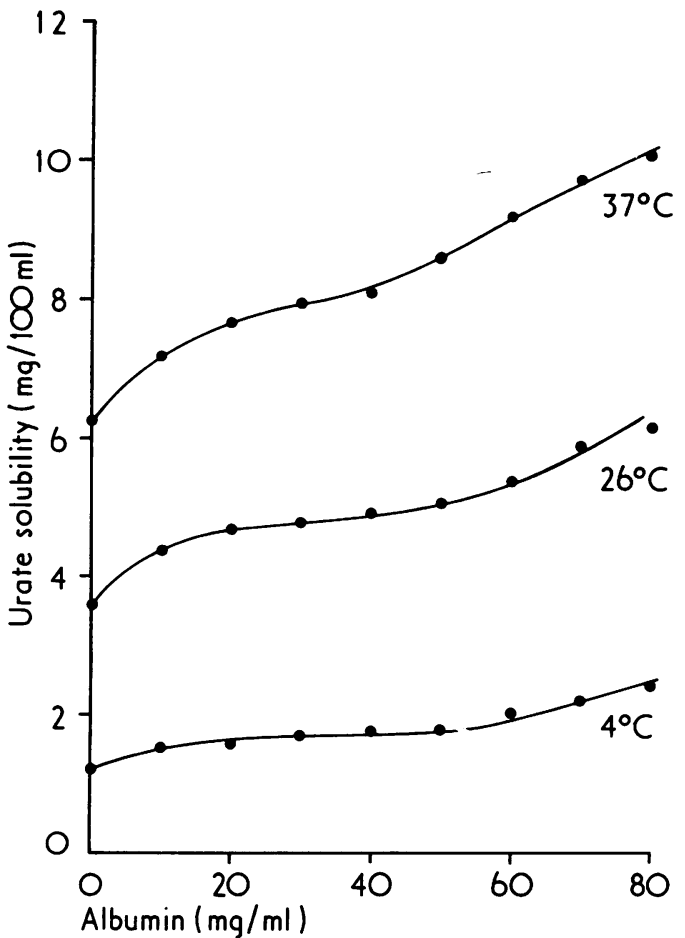

FIG. 3 Effect of human serum albumin on sodium urate solubility in 0.01 mol/l. sodium phosphate buffer containing $0.15 \mathrm{~mol} / \mathrm{l}$. sodium chloride at $37^{\circ} \mathrm{C}, 26^{\circ} \mathrm{C}$, and $4^{\circ} \mathrm{C}$. Each point represents the mean of 4 determinations. The standard error of the mean was less than 0.2 for all points except $80 \mathrm{mg} / \mathrm{ml}$ albumin at $26^{\circ} \mathrm{C}$ where it was 0.38

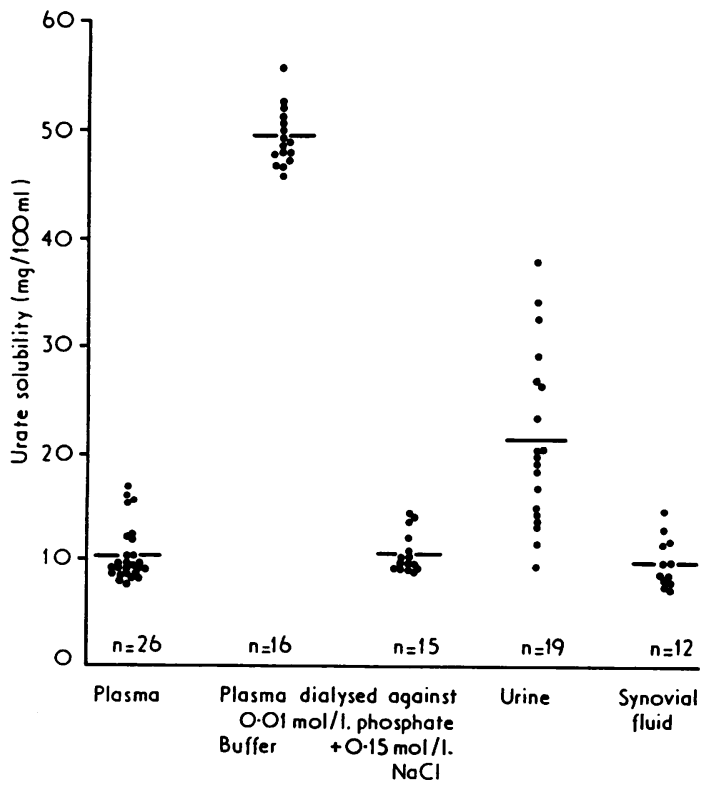

FIG. 4 Solubility of sodium urate in biological fluids. The bars represent mean values

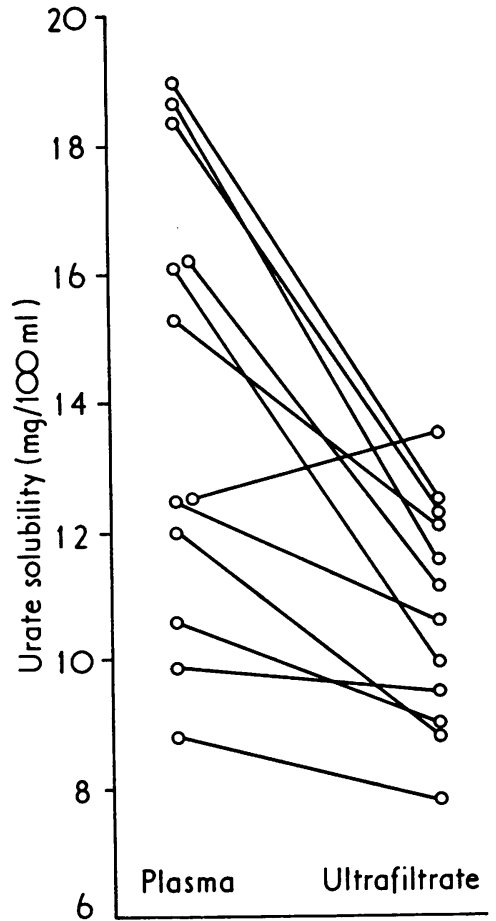

FIG.5 Effect of ultrafiltration on urate solubility in plasma at $37^{\circ} \mathrm{C}$ using sodium urate $(K \& K$ Laboratories). Lines connect the urate solubility of each ultrafiltrate with that of the plasma sample from which it was prepared

the plasma from which it was made. When comparing the plasma samples with their ultrafiltrates, the mean decrease in urate solubility resulting from ultrafiltration was $24 \%(\mathrm{P}<0.01$ using ' $\mathrm{t}$ ' test for paired data).

\section{Discussion}

When urate crystals are found in the body they tend to be located in relatively avascular and peripheral tissues. Urate crystal formation probably occurs primarily in the interstitial spaces of these tissues rather than in the plasma. In lieu of directly studying urate solubility in interstitial areas, we must define the factors altering urate solubility in buffers and accessible body fluids and extrapolate our findings to the locale of urate crystallization. Thus, the studies of the effect of sodium and albumin concentrations and pH on urate solubility in vitro show the trends to be expected in vivo rather than the absolute values.

Numerous factors can influence the in vitro urate solubility values obtained, resulting in different values being reported by different experimenters. The preparation of distilled water and crystalline monosodium urate must be carefully controlled. Some early experiments in this series were done with sodium 
urate from K\&K Laboratories. However, the solubility of this urate differed from batch to batch. Certain batches contained amorphous material which assayed as urate but showed a higher solubility (as much as $50 \%$ higher) than other K\&K batches and the urate prepared in our laboratory. The latter two urate preparations were used in all experiments except those in which the effects of sodium concentration and of ultrafiltration of plasma were studied.

It is clear that temperature plays a significant role in urate solubility and this has been discussed previously (Wilcox and others, 1972; Allen, Milosovich, and Mattocks, 1965). Loeb (1972) suggested that the predilection of gout for the peripheral parts of the body is due to sustained lower temperatures in these areas. Most of the experiments in this paper were done at $37^{\circ} \mathrm{C}$, but we have included some experiments done at $4^{\circ} \mathrm{C}$ and $26^{\circ} \mathrm{C}$, primarily to allow comparison of our results with the results of other studies done at these temperatures.

That sodium influences urate solubility has been known since at least 1892 when Roberts concluded that salt increases the solubility of uric acid in urine. Bechhold and Ziegler (1914) later showed the opposite to be true. Fig. 1 shows the effect of sodium chloride on urate solubility over a wide concentration range. The physiological range of plasma sodium falls entirely within the flat part of the curve. Thus, changes in plasma sodium would not be great enough to alter urate solubility significantly. Over the electrolyte concentration range in the body one would expect the solubility product to depend somewhat on the nature of other dissolved substances, as well as on the ionic strength itself (Bockris and Reddy, 1970). Khalaf and Wilcox (1973) found that calcium ion dramatically reduces the solubility of sodium urate in water, while potassium and cupric ion increase the urate solubility slightly. There is also evidence that urea could increase uric acid-urate solubility (Medes, 1932; Sperling, Kedem, and DeVries, 1966).

Seegmiller (1965), studying the synovial fluid from a patient with acute gout, reported a decrease in $\mathrm{pH}$ from 7.4 to 7.2 associated with a rise in lactic acid due to the high rate of glycolysis of leucocytes in the synovial fluid. This observation supported a theory that decreasing $\mathrm{pH}$ in the joint during leucocytosis decreases urate solubility slightly. Fig. 2 shows that a decrease in the $\mathrm{pH}$ from $\mathbf{7 \cdot 4}$ to $\mathbf{7 \cdot 2}$ would actually increase the urate solubility slightly. On the other hand, Khalaf and Wilcox (1973) showed that urate nucleation is enhanced by lowering the $\mathrm{pH}$.

The curves shown in Fig. 3 for the effect of albumin on urate solubility are somewhat surprising. Firstly, assuming that the increased solubility is due to binding of urate to albumin, one could predict the early portion of the curves on the basis of saturation of the urate binding sites on the albumin molecules. However, we are presently unable to explain the increased slope at albumin concentrations above $40 \mathrm{mg} / \mathrm{ml}$. Also surprising is that the magnitude of the albumininduced increase in urate solubility is greater, especially at $37^{\circ} \mathrm{C}$, than would have been predicted from experiments studying urate binding to albumin by other techniques, such as equilibrium dialysis (Klinenberg and Kippen, 1970; Farrell, Popovich, and Babb, 1971). Furthermore, our results differ markedly from those of Katz and Schubert (1970) who used a technique similar to the one used in this study to measure the effect of albumin on urate solubility. They reported that an albumin concentration of $120 \mathrm{mg} / \mathrm{ml}$ caused an increase in urate solubility of $28 \%$ (from 5.7 to $7.3 \mathrm{mg} / 100 \mathrm{ml}$ ) at $4^{\circ} \mathrm{C}$. Our Fig. 3 shows a $100 \%$ increase in urate solubility at $4{ }^{\circ} \mathrm{C}$ and a $60 \%$ increase at $37^{\circ} \mathrm{C}$ at an albumin concentration of $80 \mathrm{mg} / \mathrm{ml}$, and the magnitude of this increase would probably be the same or greater at $120 \mathrm{mg} / \mathrm{ml}$ albumin. We cannot explain the discrepancy in results between our laboratories.

As seen in Fig. 4, the high urate solubility of the plasma samples dialysed against a low ionic strength buffer shows the appreciable role of ionic strength in plasma urate solubility. Since the solubility of urate in the plasma samples dialysed against isotonic sodium phosphate buffer was about the same as in the undialysed plasma, this suggests that diffusible ions other than sodium are probably not playing a major role in the plasma solubility of urate. The variability of urate solubilities in the urine samples reflects differences in sodium concentrations and $\mathrm{pH}$. The urate solubility in synovial fluids was slightly less than in plasma. However, these fluids by their nature represent pathological conditions and may not be representative of the fluid in a normal joint space.

The comparison of urate solubility in plasma and plasma ultrafiltrates presented in Fig. 5 further substantiates the conclusion that binding of urate to plasma macromolecules may substantially increase the solubility of urate in plasma. Alvsaker (1968) reported the presence in plasma of a glycoprotein, an $\alpha 1, \alpha 2$-globulin, which may bind urate in plasma. Katz and Schubert (1970) suggested that a protein polysaccharide (PPL) similar to one found in connective tissue may increase urate solubility in plasma. However, these substances are present in plasma in minute amounts and each molecule would be required to bind large amounts of urate to produce significant increases in urate solubility. Katz and Schubert (1970) reported that PPL at a concentration of $8 \mathrm{mg} / \mathrm{ml}$ increases urate solubility by 3.5 times over a control buffer solution. However, this concentration of PPL forms an extremely viscous solution and is many times greater than could occur in plasma. By contrast, the albumin concentrations used in our study (Fig. 3) are within physiological limits. It is thus probable that albumin is the most important macromolecule in plasma with respect to increasing 
urate solubility. Of course, much higher concentrations of PPL occur in connective tissue where, as suggested by Katz and Schubert, it may play a role in urate deposition.

Of the fluids which we have studied, the plasma ultrafiltrates are perhaps most representative of the in vivo fluids where urate crystallization occurs. If the total urate concentration is the same in the interstitial fluids as in the plasma, this would favour urate crystallization in the interstitial fluids. A similar analysis might apply to the distribution of urate between plasma and synovial fluid, and there is currently some controversy as to whether or not urate levels in the synovial fluid of gouty patients are higher than in the corresponding plasma (Reeves, 1965).

The solubility studies reported in this paper were done in the presence of a large excess of urate crystals. However, it is known that if sodium urate crystals are not present then urate can form stable supersaturated solutions. Thus, hyperuricaemic fluids may remain supersaturated with urate until some mechanism causes formation of the first crystals. Urate crystal nucleation may be related to high concentrations of ions, such as calcium, in close proximity to connective tissue, or to interactions between urate and connective tissue components. Studies of these factors are currently proceeding in our laboratories.

\section{Summary}

Urate solubility was measured in buffers and body fluids. At physiological concentrations of sodium chloride, urate solubility was less than $10 \%$ of the saltfree value. Minimum urate solubility occurred between $\mathrm{pH} 7.0$ and 10.0 and increased with increasing or decreasing $\mathrm{pH}$. Addition of $50 \mathrm{mg} / \mathrm{ml}$ human albumin to buffer caused a $41 \%$ increase in urate solubility at $37^{\circ} \mathrm{C}$. The solubility of urate $(\mathrm{mg} / 100 \mathrm{ml})$ in biological fluids was: plasma 10.6 \pm 0.5 (mean \pm $\mathrm{SE}$ ); urine $21.4 \pm 1.9$; and synoval fluid $10 \cdot 0 \pm 0.7$. Urate may precipitate preferentially in interstitial fluids partly because of the lack of protein molecules to bind it.

We thank Heddy Van Lingen and Scott Broffman for their expert technical assistance, and Dr. Michael Whitehouse for continued advice and encouragement. These studies were supported by grants from the National Institutes of Health (GM-15759, 5 T01 GM 02040-04, and RR-05468) and the National Science Foundation (GK-17042).

\section{References}

Allen, D. J., Milosovich, G., AND Mattocks, A. M. (1965) Arthr. and Rheum., 8, 1123 (Inhibition of monosodium urate needle crystal growth)

Alvsaker, J. O. (1968) J. clin. Invest., 47, 1254 (Genetic studies in primary gout. Investigations on the plasma levels of the urate binding $\alpha 1-\alpha 2$-globulin in individuals from two gouty kindreds)

BeCHHOLD, H., AND ZieGler, J. (1914) Biochem. Z., 64, 471 (Vorstudien über Gicht)

BLuestone, R., KipPen, I., AND KLINENBeRg, J. R. (1969) Brit. med. J., 4, 590 (Effect of drugs on urate binding to plasma proteins)

BoCKRIS, J. O'M., AND REDDY, A. K. N. (1970) In 'Modern Electrochemistry', p. 270. Plenum, New York

Buchanan, W. W., Kuinenberg, J. R., AND Seegmiller, J. E. (1965) Arthr. and Rheum., 8, 361 (The inflammatory response to injected microcrystalline monosodium urate in normal, hyperuricemic, gouty, and uremic subjects)

Farrell, P. C., Popovich, R. P., AND BabB, A. L. (1971) Biochim. biophys. Acta, 243, 49 (Binding levels of urate ions in human serum albumin and plasma)

Katz, W. A., AND Schubert, M. (1970) J. clin. Invest., 49, 1783 (The interaction of monosodium urate with connective tissue components)

Khalaf, A. A., AND Wilcox, W. R. (1973) J. Crystal Growth, 20, 227 (Solubility and nucleation of monosodium urate in relation to gouty arthritis)

KuINenberg, J. R., AND KiPPEN, I. (1970) J. Lab. clin. Med., 75, 503 (The binding of urate to plasma proteins determined by means of equilibrium dialysis)

Liddle, L., Seegmiller, J. E., AND LASTER, L. (1959) Ibid., 54, 903 (The enzymatic spectrophotometric method for determination of uric acid)

LOEB, J. N. (1972) Arthr. and Rheum., 15, 189 (The influence of temperature on the solubility of monosodium urate)

Medes, G. (1932) Proc. Soc. exp. Biol. (N.Y.), 30, 281 (Solubility of calcium oxolate and uric acid in solutions of urea)

ReEves, B. (1965) Ann. rheum. Dis., 24, 569 (Significance of joint fluid uric acid levels in gout)

ROBERTS, W. (1892) Brit. med. J., 1, 1347 (The chemistry and therapeutics of uric acid gravel and gout)

SeEgmiler, J. E. (1965) Arthr. and Rheum., 8, 714 (The acute attack of gouty arthritis)

Sperling, O., Kedem, O., ANd DeVries, A. (1966) Rev. franç. Étud. clin. biol., 11, 40 (Etiologie de la lithiase urique. I. Solubilité de l'acide urique et de l'urate de sodium en solution tampon)

Whitehouse, M. W., Kippen, I., and Klinenderg, J. R. (1971) Biochem. Pharmacol., 20, 3309 (Biochemical properties of anti-inflammatory drugs. XII. Inhibition of urate binding to human albumin by salicylate and phenylbutazone analogues and some novel anti-inflammatory drugs)

Wilcox, W. R., Khalaf, A., Weinberger, A., Kippen, I., AND Klinenberg, J. R. (1972) Med. biol. Engng., 10, 522 (Solubility of uric acid and monosodium urate) 